\title{
Clinical and Angiographic Outcomes of Endovascular Treatment for Ruptured Posterior Circulation Cerebral Aneurysms
}

\author{
Jihui LIU, Xinguo LI, Shengxue SUN, Yunjie WANG, Peizhuo ZANG \\ The First Affiliated Hospital of China Medical University, Department of Neurosurgery, Shenyang, China
}

\section{ABSTRACT}

AIM: To report the angiographic and clinical results achieved in endovascular treatment of ruptured posterior circulation cerebral aneurysms over a 3-year period.

MATERIAL and METHODS: A retrospective analysis of 45 patients was performed between June 2008 and June 2011 . Clinical follow-up was achieved in all patients, with a mean duration of 17 months. Angiographic follow-up was obtained in $88.9 \%$ of cases, with a mean duration of 7.2 months.

RESULTS: A clinical improvement, or stable outcome was achieved in all patients. There was one case of re-bleeding as a periprocedural complication 2 days after incomplete stent-assisted coiling of a vertebral artery aneurysm. There was no death in our patients. In 40 of the 45 patients (88.9\%), angiographic follow-up was obtained at a mean of 7.2 months (range, 1 to 24 months). Recurrences in 5 patients (12.5\%) at 2 days, 3, 6, 8, and 13 months required re-treatment.

CONCLUSION: Endovascular embolization is an attractive option for ruptured posterior circulation aneurysms with stable long-term outcome. This study confirmed that endovascular treatment is associated with low mobidity and mortality. However, re-canalization may be observed up to 2 years after the initial obliteration. Long-term follow-up with angiography is needed.

KEYWORDS: Cerebral aneurysm, Embolization, Posterior circulation, Outcome, Subarachnoid hemorrhage

\section{INTRODUCTION}

The incidence of microsurgical treatment of posterior circulation aneurysms has decreased while endovascular treatment has increased $(1,3,10,19)$, resulting from the International Study of Unruptured Intracranial Aneurysms (ISUIA) (13), which assumed high morbidity in microsurgical patients, and the International Subarachnoid Aneurysm Trial (ISAT) that showed a more favorable neurological outcomes with endovascular treatment than that with microsurgical treatment (10). Only $2.7 \%$ cases were posterior circulation aneurysms in ISAT and clinical outcome data was not described for these patients (10). The perception that endovascular treatment was better for posterior circulation aneurysms may have come from
ISUIA, but data was limited (16). A therapeutic advantage in posterior circulation aneurysms was apparent in large aneurysms (diameter, 13-24 mm) and poor outcomes were associated with aneurysm size and patient age (13).

Here, we present our experience in the endovascular treatment of ruptured posterior circulation aneurysms and confirm the low morbidity and mortality.

\section{MATERIAL and METHODS}

From June 2008 to June 2011, 45 patients with acute or subacute subarachnoid hemorrhage $(\mathrm{SAH})$ from ruptured posterior circulation aneurysms were evaluated for endovascular treat- 
ment. Their procedure reports, computed tomography (CT), magnetic resonance imaging (MRI) scans and angiograms were retrospectively reviewed. Clinical follow-up examination was supplemented by telephone interviews. All patients in this series had an acute or subacute SAH and they were classified according to Hunt and Hess grading system (4). Quantitative measurement of aneurysm size was performed with the use of a 3 dimensional (3D) workstation. The review included aneurysmal shape, degree of sac occlusion, and extent of aneurysm recurrence. During initial treatment, the angiographic projections of the aneurysm were used. The rates of aneurysm occlusion were determined in subsequent followup studies. A modification of the Raymond classification scale was used to measure aneurysm occlusion immediately after angiography (4). Clinical condition at presentation was determined by the Hunt-Hess grading system (4). Clinical outcome at follow-up was classified with the Glasgow Outcome Scale (GOS) (5). Clinical data were obtained from examinations conducted by stroke neurologists or neurosurgeons before and after the procedure. Clinical data were obtained from neurological examinations during follow-up angiographic studies, from examinations by patients' referring neurosurgeons and neurologists, and by telephone interviews. All treatment was performed under general anesthesia. A 6F arterial sheath was used in the right common femoral artery. Diagnostic angiography was performed using a $5 \mathrm{~F}$ catheter to evaluate the aneurysm and extent of vasospasm and other cerebral vascular anomalies. When patients received endovascular treatment, one of 3 types of endovascular treatment, "simple coiling" for aneurysms with a small neck, and "deconstructive" or "reconstructive" for wide-necked aneurysms, was selected. Deconstructive treatment was performed by proximal coil occlusion or internal coil trapping of the parent artery. Reconstructive treatment was performed using 1 to 2 overlapping stents, with or without coiling. The treatment modality was decided according to the patient's presentation, aneurysm shape, and anatomy of the vertebrobasilar artery. Self-expanding neurovascular stents (Neuroform, Boston Scientifics, or Enterprise, Codman) were preferably used. Patients with stenting received a loading dose of antiplatelet premedication $(300 \mathrm{mg}$ of clopidogrel) for 2 hours before treatment and dual antiplatelet medication (100 mg of aspirin and $75 \mathrm{mg}$ of clopidogrel) after the procedure. Dual antiplatelet medication was maintained for 4 weeks and then was changed to aspirin monotherapy indefinitely.

\section{RESULTS}

There were 24 men $(53.3 \%)$ and 21 women (46.7\%). Ages ranged from 18 to 71 years (mean age, 47.1 years). The median time of initial SAH to endovascular treatment was 5 days. Thirty-four patients $(75.6 \%)$ were Hunt-Hess grade I (Figures 1A, B; 2A, B), $3(6.7 \%)$ grade II, 6 (13.3\%) grade III (Figure 3A, B) and 2 (4.4\%) grade IV. The most prevalent aneurysm location was at the intracranial vertebral artery in 23 patients $(51.1 \%)$ followed by the posterior cerebral artery in 7 patients $(15.6 \%)$, basilar bifurcation in 5 patients $(11.1 \%)$, basilar trunk in 5 patients (11.1\%), vertebro-basilar artery junction in 4 patients (8.9\%) and other location in 3 patients
(6.7\%) (Table I). Among the treated aneurysms, 6 (12.5\%) were saccular with a narrow neck $(<4 \mathrm{~mm}), 12(25 \%)$ were wide-necked $(>4 \mathrm{~mm})$ saccular and $30(62.5 \%)$ were fusiform aneurysms. Mean aneurysm size was $7.2 \pm 4.35 \mathrm{~mm}$. On postprocedural angiogram, 38 of $48(79.2 \%)$ aneurysms treated with coiling, parent vessel occlusion or stent-assisted coiling were occluded without remnant. Eight aneurysms treated with coiling or stent-assisted coiling showed subtotal occlusion. Eight aneurysms were subtotally occluded, 6 with residual dome filling (Raymond Class 3), the other 2 with filling of a residual base (Raymond Class 2). Contrast residual time within the aneurysm was increased moderately after the stent placement in 2 patients treated by stenting alone. In 43 of 45 patients (95.5\%), excellent clinical and technical results were obtained without any procedure-related complications. There were 2 cases of minor permanent morbidity (2 of $45(4.4 \%)$ ), and no mortality. In total, 43 patients $(95.5 \%)$ retained no permanent deficits and returned to their baseline neurological examination. The 2 cases of permanent minor morbidity caused by initial SAH did recover during follow-up period. Follow-up angiograms were achieved in 40 patients (88.9\%) at 1 to 24 months (average 7.2 months). These 40 patients harboured 42 aneurysms. Thirty-five patients $(87.5 \%)$ remained stable during the entire observation period. Five aneurysms in 5 patients showed re-canalization, all of which were treated initially with stent-assisted coiling. Of the 2 aneurysms treated with stenting alone, follow-up angiography was obtained, which one demonstrated complete aneurysm occlusion without re-canalization and one showed no change in shape during the observation period. These included 2 vertebral artery fusiform aneurysms. Five recurrences $(12.5 \%)$ required re-treatment. One vertebral artery fusiform aneurysm was recoiled and stented again at 6-month follow-up, because of delayed growth of a small pseudoaneurysm proximal to the previously treated area. Another 2 vertebral artery fusiform aneurysms in 2 patients showed re-canalization on 8- and 13

Table I: Distribution of Ruptured Posterior Circulation Cerebral Aneurysms

\begin{tabular}{lc}
\hline Locations & Number (\%) \\
\hline Intracranial vertebral artery & $23(51.1 \%)$ \\
\hline Basilar tip & $5(11.1 \%)$ \\
\hline Basilar trunk & $5(11.1 \%)$ \\
\hline Vertebro-basilar junction & $4(8.9 \%)$ \\
\hline PCA-P1 & $3(6.7 \%)$ \\
\hline PCA-P2 & $2(4.4 \%)$ \\
\hline PCA-P3 & $3(4.4 \%)$ \\
\hline SCA & $1(2.2 \%)$ \\
\hline AICA & $1(2.2 \%)$ \\
\hline PICA & $1(2.2 \%)$ \\
\hline
\end{tabular}

PCA: Posterior cerebral artery, SCA: Superior cerebellar artery, AICA: Anterior inferior cerebellar artery, PICA: Posterior inferior cerebellar artery. 

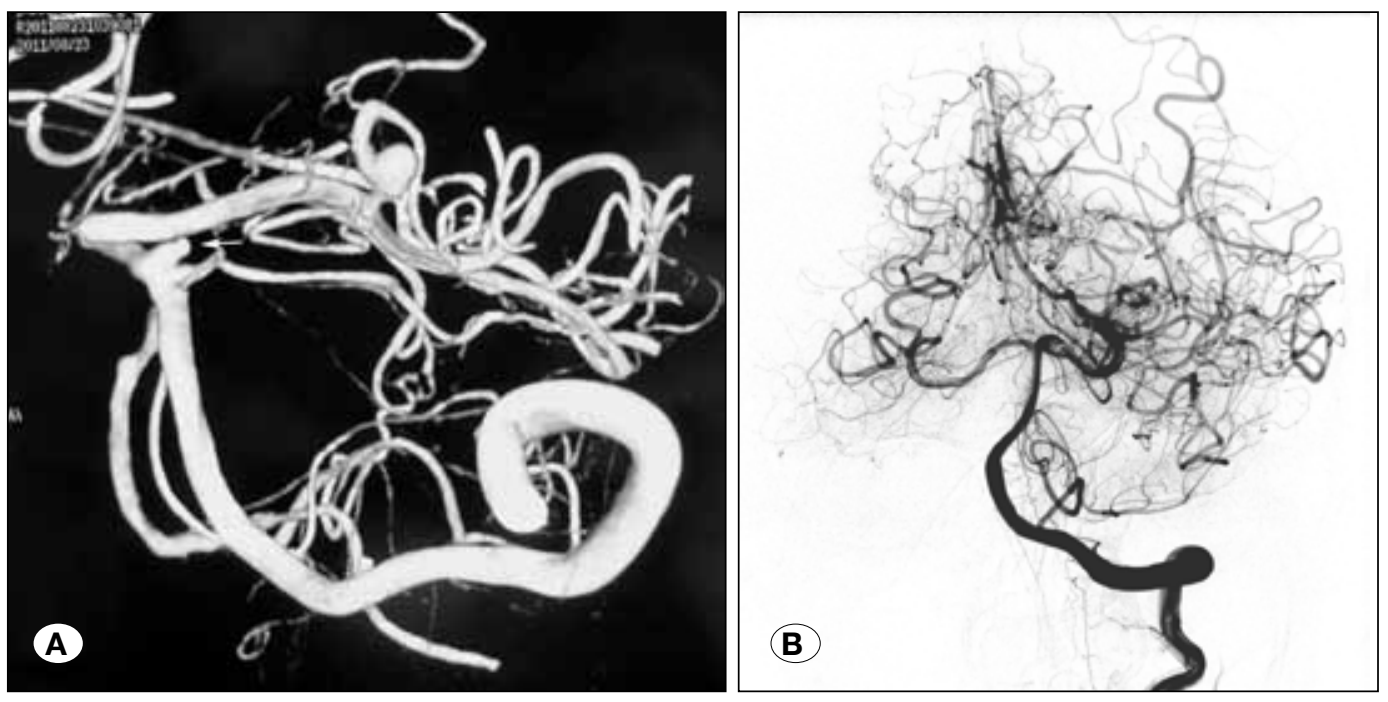

Figure 1: A 69-year-old woman suffered a HuntHess grade I SAH. A) 3-D reconstruction of the left vertebral artery injection revealed a basilar tip (arrow) and a PCA-P2 aneurysm. The basilar tip aneurysm was wide-necked and was considered to rupture because of its irregular shape. B) The PCA-P2 aneurysm was simply coiled and the basilar tip aneurysm was treated with Enterprise stent-assisted coiling, as shown by the posttreatment angiogram.
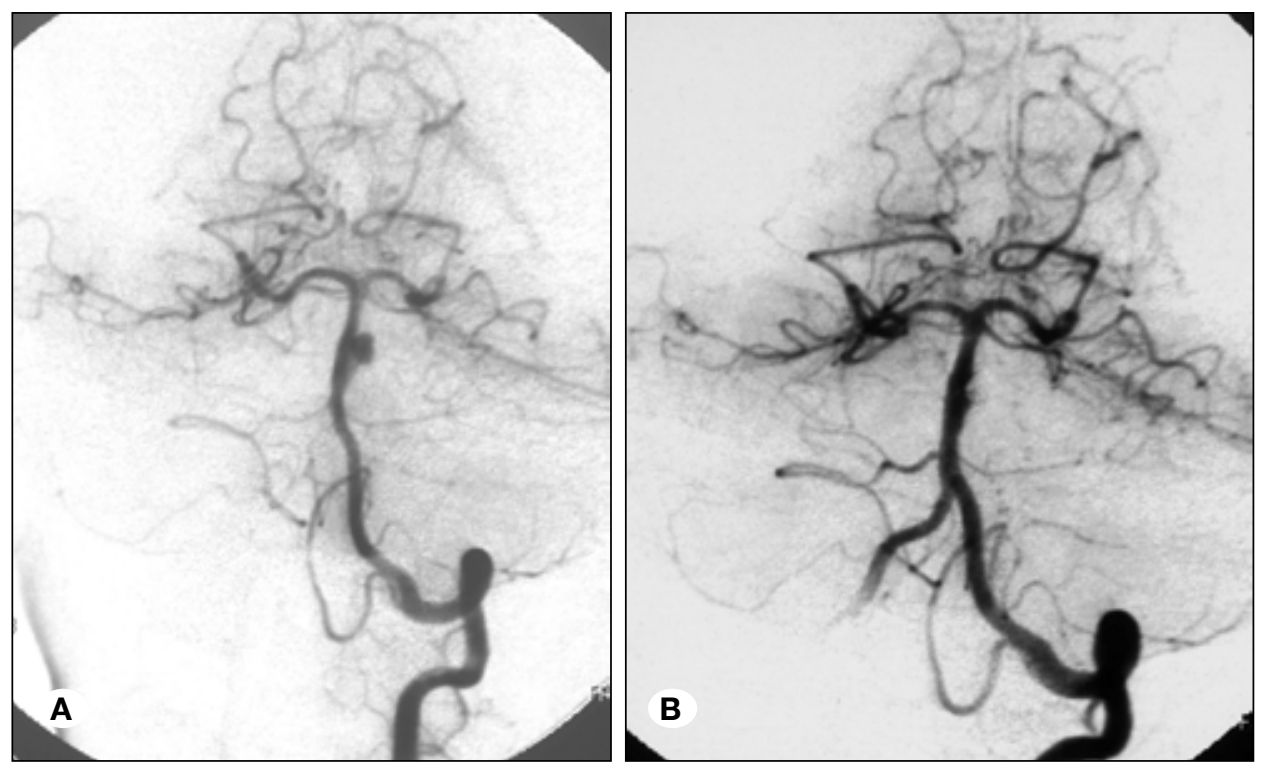

Figure 2: A 28-year-old woman suffered a Hunt-Hess grade I SAH. A) The left vertebral artery angiogram revealed a wide-necked basilar trunk aneurysm. B) The aneurysm was treated with Leo stent-assisted coiling, as shown by the posttreatment angiogram.
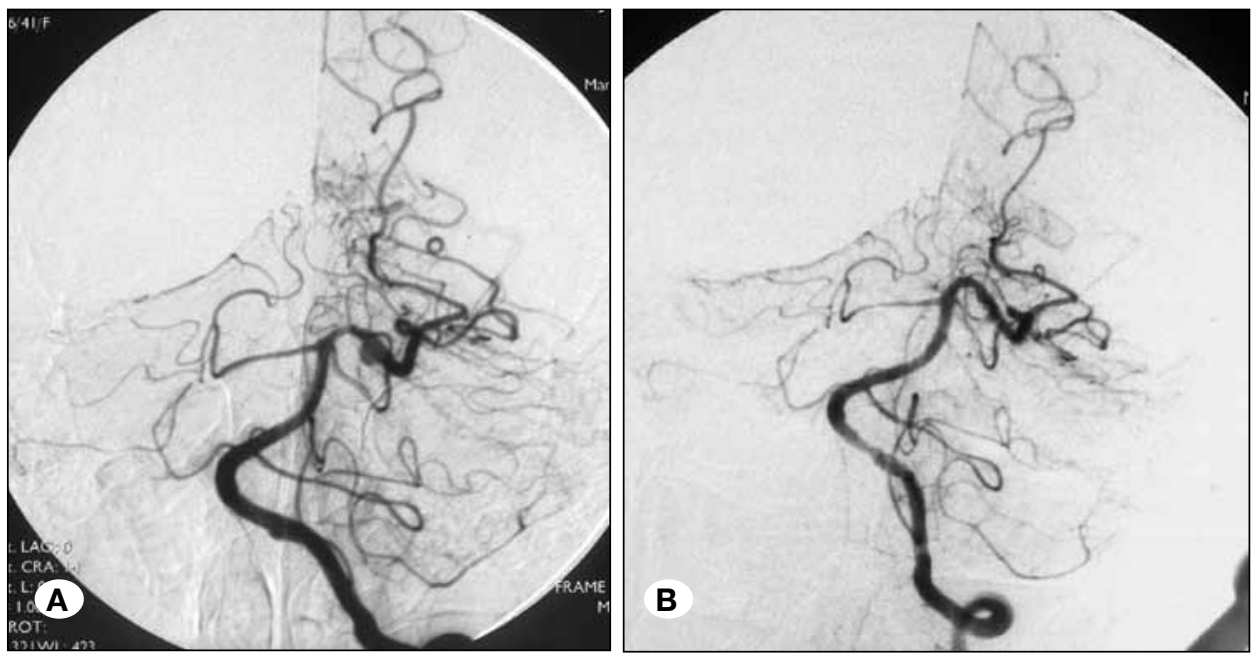

Figure 3: A 40-year-old woman suffered a Hunt-Hess grade III SAH. A) Injection of the left vertebral artery outlines a wide-necked PCA-P1 aneurysm. The aneurysm was treated by Neuroform stent-assisted coiling. B) The post-treatment angiogram showed complete occlusion of the aneurysm. 
-month follow-up angiograms. Re-coiling was successfully performed and further follow-up at 10 and 15 months showed no further recurrence. In the fourth retreated patient, a fusiform vertebral artery aneurysm involving the posterior inferior cerebellar artery (PICA) that was initially treated by stent and coils showed $3-\mathrm{mm}$ filling of residual base to preserve the origin of the PICA. This aneurysm re-bled on postprocedure day 2 and the re-coiling with complete obliteration of the pseudoaneurysm, but leaving approximately $10 \%$ of the residual base of the aneurysm to preserve the origin of the PICA; no permanent neurological deficits were encountered. Another re-canalized basilar artery tip aneurysm was recoiled at 3-month follow-up and further follow-up at 12 months after the recoiling (15 months after the initial intervention) showed no further re-canalization. Follow-up clinical examination was achieved in all 45 patients at average 19.2 months (range from 1 to 43 months). All patients had no new post-procedural deficit and showed significant improvement in their presenting symptoms.

\section{DISCUSSION}

Untreated ruptured aneurysms have a $37 \%$ risk of re-bleeding at 4 weeks resulting an overall mortality and morbidity of $34 \%$ to $42 \%(1,12)$. Our results suggested that endovascular therapy offers a protective effect contrast to this dismal natural history. One re-bleeding in the acute phase occurred after incomplete stent-assisted coiling resulting a 2.2\% (1/45 patients) rate of recurrent SAH. Furthermore, no aneurysm ruptured during follow-up period. This was a rate similar to those reported in other endovascular series, which range from $0.1 \% /$ year to $3.4 \% /$ year $(2,6,11,18)$. Johnston et al. measured the rate of recurrent SAH at $1.90 \%$ in a group of 1001 patients treated with coil embolization or surgical clipping during a follow-up period of 4 years (6).

Wermer et al. measured the cumulative incidence of recurrent SAH was $3.2 \%$ in the first 10 years after the initial SAH in a group of 752 patients treated with surgical clipping (22). Risk factors of recurrent SAH were smoking, older age and multiple aneurysms at the time of the initial SAH. The initial clinical grade at presentation strongly predicted patient outcome $(9,14)$. In one series, Hunt-Hess grade III patients predictably had a lower incidence of GOS I outcome (78\%). More than $90 \%$ of Hunt-Hess grade I or II patients had a good recovery leading to a GOS I outcome at final follow-up (9). Fewer patients recovered to a good final outcome in Hunt-Hess grade IV and V patients: GOS I outcomes were achieved in only $46 \%$ of Hunt-Hess grade IV cases and in only $25 \%$ of Hunt-Hess grade $\mathrm{V}$ patients (9). Clinical deterioration that resulted from medical problems $(7.3 \%)$, vasospasm (8.3\%), and early and delayed complications (1.8\%) have been reported (9). Our overall final excellent clinical outcome (GOS I) was $95.6 \%$ and good (GOS II) was $4.4 \%$. In this series, $82.2 \%$ patients were of good-grade (Hunt-Hess grade I or II) and this may associated with our favorable clinical outcomes. Contrast to $2.8 \%$ to $5.1 \%$ complication rate in other endovascular series $(14,20)$, there was no procedure-related complication in our series.
Although ISAT demonstrated neurological outcomes with endovascular coiling that were better than with microsurgical clipping (10). Recent long-term follow-up of ISAT (11) have showed an increased risk of recurrent bleeding from a coiled aneurysm compared with a clipped aneurysm. The risk of death at 5 years was significantly lower in the coiled group than the clipped group. Another surgical series by Sanai et al. (17) describes the results of 217 selected aneurysms of the posterior circulation, $80.6 \%$ were ruptured. $66 \%$ of patients were determined to be neurologically intact or have mild nonlimiting deficits (GOS I and II) at 13.6-month follow-up. Of the 171 aneurysms that were clipped directly, 167 (97.7\%) were eliminated angiographically. In our study, there is a higher part of good-grade patients than that of Lempert et al. (9) (7\% Hunt- Hess grade IV and V versus $22 \%$ ) and Sanai et al. (17) (10.6\% Hunt-Hess grade IV and V versus $2.3 \%)$. In one prospective randomized trial of surgery versus endovascular therapy in 109 patients, Vanninen et al. (21) described $83 \%$ of coil-treated patients with posterior circulation aneurysm with GOS I and II scores compared with $60 \%$ of surgical patients at 3 months. Kassel et al. $(7,8)$ reported an overall good recovery in $52.6 \%$, a $7.9 \%$ incidence of severely disabled/vegetative outcome and death rate of $31.2 \%$. Other surgical series $(15,17,19)$ reported mortality of $6 \%$ to $11 \%$ and morbidity of $10 \%$. Our study is limited by the small number of cases, but it failed to detect a statistically significant difference in final outcome.

\section{CONCLUSION}

Endovascular treatment modalities are good and safe options for ruptured posterior circulation aneurysms. However, longterm follow-up angiography is needed because the risk of recurrence found up to 2 years after the initial treatment. Future studies are needed to balance the extended long-term outcome and efficacy of endovascular therapy and surgical clipping.

\section{REFERENCES}

1. Batjer HH, Samson DS: Causes of morbidity and mortality from surgery of aneurysms of the distal basilar artery. Neurosurgery 25: 904-916, 1989

2. Bodily KD, Cloft HJ, Lanzino G, Fiorella DJ, White PM, Kallmes DF: Stent-assisted coiling in acutely ruptured intracranial aneurysms: A qualitative, systematic review of the literature. AJNR Am J Neuroradiol 32(7):1232-1236, 2011

3. Chung J, Park H, Lim YC, Hyun DK, Shin YS: Endovascular treatment of basilar artery trunk aneurysms. Acta Neurochir (Wien) 153(11): 2137-2145, 2011

4. Hunt WE, Hess RM: Surgical risks as related to time of intervention in the repair of intracranial aneurysms. J Neurosurg 28:14-20, 1968

5. Jennett $B$, Bond $M$ : Assessment of outcome after severe brain damage. Lancet 1(7905): 480-484, 1975

6. Johnston SC, Dowd CF, Higashida R: Predictors of rehemorrhage after treatment of ruptured intracranial aneurysms: The Cerebral Aneurysm Rerupture After Treatment (CARAT) study. Stroke 39: 120-125, 2008 
7. Kassell NF, Torner JC, Haley EC Jr, Jane JA, Adams HP, Kongable GL: The international cooperative study on the timing of aneurysm surgery, part 1: Overall management results. J Neurosurg 73:18-36, 1990

8. Kassell NF, Torner JC, Jane JA, Haley EC Jr, Adams HP: The international cooperative study on the timing of aneurysm surgery, part 2: Surgical results. J Neurosurg 73:37-47, 1990

9. Lempert TE, Malek AM, Halbach VV, Phatouros CC, Meyers PM, Dowd CF, Higashida RT: Endovascular treatment of ruptured posterior circulation cerebral aneurysms. Clinical and Angiographic Outcomes. Stroke 31:100-110, 2000

10. Molyneux A, Kerr R, Stratton I, Sandercock P, Clarke M, Shrimpton J, Holman R, International Subarachnoid Aneurysm Trial (ISAT) Collaborative Group: International Subarachnoid Aneurysm Trial (ISAT) of neurosurgical clipping versus endovascular coiling in 2143 patients with ruptured intracranial aneurysms: A randomised trial. Lancet 360:12671274, 2002

11. Molyneux AJ, Kerr RS, Birks J, Ramzi N, Yarnold J, Sneade M, Rischmiller J; ISAT Collaborators: Risk of recurrent subarachnoid haemorrhage, death, or dependence and standardised mortality ratios after clipping or coiling of an intracranial aneurysm in the International Subarachnoid Aneurysm Trial (ISAT): Long-term follow-up. Lancet Neurol 8(5):427-433, 2009

12. Nishioka H, Torner JC, Graf CJ, Kassell NF, Sahs AL, Goettler LC: Cooperative study of intracranial aneurysms and subarachnoid hemorrhage: A long-term prognostic study, II: Ruptured intracranial aneurysms managed conservatively. Arch Neurol 41:1142-1146, 1984

13. Ogilvy CS, Cheung AC, Mitha AP, Hoh BL, Carter BS: Outcomes for surgical and endovascular management of intracranial aneurysms using a comprehensive grading system. Neurosurgery 59(5):1037-1043, 2006
14. Pandey AS, Koebbe C, Rosenwasser RH, Veznedaroglu E: Endovascular coil embolization of ruptured and unruptured posterior circulation aneurysms: Review of a 10-year experience. Neurosurgery 60:626-637, 2007

15. Peerless SJ, Hernesniemi JA, Gutman FB, Drake CG: Early surgery for ruptured vertebrobasilar aneurysms. J Neurosurg 80:643-649, 1994

16. Raymond J, Guilbert F, Weill A, Georganos SA, Juravsky L, Lambert A, Lamoureux J, Chagnon M, Roy D: Long-term angiographic recurrences after selective endovascular treatment of aneurysms with detachable coils. Stroke 34:1398-1403, 2003

17. Sanai N, Tarapore P, Lee AC, Lawton MT: The current role of microsurgery for posterior circulation aneurysms: A selective approach in the endovascular era. Neurosurgery 62:12361253,2008

18. Sluzewski M, van Rooij WJ, Beute GN, Nijssen PC: Late rebleeding of ruptured intracranial aneurysms treated with detachable coils. AJNR Am J Neuroradiol 26: 2542-2549, 2005

19. Sugita K, Kobayashi S, Shintani A, Mutsuga $\mathrm{N}$ : Microneurosurgery for aneurysms of the basilar artery. J Neurosurg 51:615-620, 1979

20. Tähtinen OI, Vanninen RL, Manninen HI, Rautio R, Haapanen A, Niskakangas T, Rinne J, Keski-Nisula L: Wide-necked intracranial aneurysms: Treatment with stent-assisted coil embolization during acute $(<72$ hours) subarachnoid hemorrhage-experience in 61 consecutive patients. Radiology 253(1):199-208, 2009

21. Vanninen R, Koivisto T, Saari T, Hernesniemi J, Vapalahti M: Ruptured intracranial aneurysms: Acute endovascular treatment with electrolytically detachable coils: A prospective randomized study. Radiology 211:325-336, 1999

22. Wermer MJ, Greebe P, Algra A, Rinkel G: Incidence of recurrent subarachnoid haemorrhage after clipping for ruptured intracranial aneurysms. Stroke 36:2394-2399, 2005 